\title{
Implementing Flexible Scheduling in Elementary Libraries
}

\author{
Joy H. McGregor, Ph.D. \\ $<$ <joymal@gte.net> \\ Associate Professor, School of Library and Information Studies \\ Texas Woman's University \\ United States of America
}

Flexible scheduling in school libraries can provide a mechanism for achieving the learning goals and objectives of both the school library program and the curriculum by making information available at the point of need and by promoting use of the library and its services at a relevant moment instead of on a predetermined schedule. This study examined the successful implementation of flexible scheduling in six elementary schools where no funding was received to support implementation. Telephone interviews with librarians, principals, and teachers provided the data. The preliminary results indicate that, in those schools with successful implementations, flexible scheduling was only a tool to achieve another internal curricular objective, such as curriculum integration or literacy improvement. In addition, education of stakeholders is essential; and it must emphasize strategies for effective use of the programs supported by flexible scheduling and their potential learning outcomes rather than simply provide information on how flexible scheduling works.

\section{Introduction}

Based on a history of educational research showing that learning is most effective at the point of need, flexible scheduling in school libraries can be seen as an effective model for achieving the learning goals and objectives of both the school library program and the curriculum. Jean Donham van Deusen and Julie Tallman studied flexible scheduling through a national survey funded by the AASL/Highsmith Research Grant in 1994. Their research provided valuable information about the extent of flexible scheduling in school libraries and the degree to which curriculum consultation and information skills instruction occurred in school libraries using fixed, flexible, or mixed scheduling. They found that more positive environments for curriculum consultation and teaching activity existed where a) principals expected team planning in libraries with flexible or mixed scheduling, b) principals expected school librarians to meet with teaching teams, and c) librarians were fulltime and did not cover teacher planning time. They also found that collaboratively planned and taught units were more common in flexibly scheduled libraries where at least one formal planning session occurred (Donham van Deusen \& Tallman, 1994).

In 1997, a study by Ken Haycock of Canadian school libraries confirmed Donham van Deusen and Tallman's findings. He suggested that flexible scheduling might be "more indicative of leadership practices and collaborative activities than having a causal relationship with consultative tasks" (Haycock, 1998, p. 23). 
These findings are useful as support for implementing flexible scheduling in order to encourage curriculum consultation and effective information skills teaching. However, little is known about effective implementation of flexible scheduling. Based on her previous research,

Donham van Deusen suggested that several conditions must exist for flexible scheduling to be implemented successfully. These are:

- an information skills curriculum matched with the content area curriculum

- flexible access to the library media center

- team planning

- principal expectations for collaboration with teachers

- a commitment to resource-based learning (1995, p. 17-18)

Donham van Deusen also suggested two factors that might enhance flexible scheduling implementation: adequate support staff and an assessment plan for the school library media center (1995, p. 18). There has been non in-depth study of the actual importance of these factors, however.

Library Power, a project funded by the DeWitt-Wallace Readers Digest Fund, created flexibly scheduled school libraries in nineteen communities across the United States. Dianne Hopkins and Douglas Zweizig have evaluated this program through case studies, questionnaires, and extensive documentation of practice. Flexible scheduling was a requirement for participation in the Library Power program and the evaluation showed that "for many ... teachers, experience with the flexible schedule was required for them to have some sense of the benefits it could bring their teaching" (Zweizig, 1999, p. 20). Principals were often credited with making flexible scheduling work by providing strong support and by devising creative solutions to the problem of providing planning time for both teachers and librarians (Zweizig, 1999).

Donna Shannon investigated the development of flexible scheduling in two Library Power schools in Kentucky. She, too, found that changing the way teachers think about scheduling their classes into the library was the biggest challenge (Shannon, 1996). These studies reveal a great deal about implementation of flexible scheduling in situations where significant monies are provided for such implementation. Most schools around the world, however, do not receive extra funding contingent on implementing flexible scheduling. In schools where no mandate related to funding exists, how and why does implementation of flexible scheduling occur? What effects do school librarians, administrators, and teachers observe in these situations?

This research project examined the implementation of flexible scheduling in elementary schools where the incentive for implementation was not access to additional funding. Elementary schools were selected for study since flexible scheduling seems to have been more difficult to implement there than in secondary schools. The purpose of the study was to explore effective flexible scheduling implementation in elementary school library media centers, to determine how successful implementation occurs, and factors that impact that success. When school-based stakeholders (librarians, teachers, and administrators) agree that flexible scheduling has been successfully implemented and has positive benefits, on what do they base that claim? While the 
study did not strive to prove outcomes of flexible scheduling, such as the impact of flexible scheduling on learning, it does include anecdotal evidence of some of those outcomes.

\section{Research Questions}

The primary objective of this pilot study is to add to the knowledge of what makes flexible scheduling work, so that elementary school librarians struggling with implementation can determine the source of their implementation problems and better identify solutions. It provides a basis for further exploration of the concept. The study also includes an examination of the impact of this implementation process on learning, as well as the variables that impact implementation itself.

The specific research questions were:

- Why was flexible scheduling implemented in elementary schools where funding was not contingent on flexible scheduling?

- What factors influence the implementation?

- On what do stakeholders base their claim for success of the implementation?

\section{Methodology}

A preliminary Delphi study established the concepts and ideas to be explored during the current study. Delphi participants were district coordinators who had been instrumental in implementing or expanding implementation of flexible scheduling in their school districts. These experts provided rich data on many aspects of flexible scheduling implementation, such as support for flexible scheduling; the necessity and effect of pre-existing factors; the importance of teachers' and school librarians' understandings of the concept and the advantages; ongoing needs during implementation; barriers to implementation; and the importance of a number of variables such as school size, clerical help, and teaching philosophies. These responses were used to frame questions for participants in the current study.

\section{Population}

The current study, partially funded by the IASL Takeshi Murofushi Research Award and the AASL/Highsmith Research Grant, involved personnel from six schools in widely dispersed school districts and with diverse characteristics. School librarians were identified as the primary source of data for this study, and also as the logical gatekeepers to approach to find participants. Several expert groups in the United States provided suggestions of school librarians working in schools in which flexible scheduling had existed for at least two years, and in which the current school librarian had been responsible for implementation of flexible scheduling. In addition, the schools were not part of the Library Power initiative. The leadership of the American Association of School Librarians, school library educators, and the original Delphi participants 
made recommendations. Potential participants were also invited to identify themselves through the LM_NET discussion list. Together these sources identified twenty-one school librarians as potential participants in the study. Criteria to select the final six participants were:

- flexible scheduling must have been in place for at least two years

- the principal was willing to be interviewed

- the current librarian had been responsible for implementation of flexible scheduling

- the librarian believed that there would be substantial agreement among teachers and administrators that flexible scheduling implementation had been successful.

School librarians were contacted and asked to respond to the first three criteria. If those criteria were met, then all teachers in their schools received a simple, one-question questionnaire that stated "The implementation of flexible scheduling in our library has been successful" and were asked to choose a response ranging from Strongly Agree to Strongly Disagree. Schools in which the responses indicated $75 \%$ or more agreement with that statement were selected. The final determination was based on attempting to represent a wide variety of situations so that many who would potentially use the findings might have a basis for comparison. Obviously, it was impossible with such a small sample to represent all variations.

Table 1. Participant schools.

\begin{tabular}{|c|c|c|c|c|c|c|}
\hline $\begin{array}{c}\text { Public/ } \\
\text { Private }\end{array}$ & Grades & $\begin{array}{c}\text { Socio-economic or } \\
\text { Other Relevant } \\
\text { Descriptor }\end{array}$ & $\begin{array}{c}\text { Number of } \\
\text { Students }\end{array}$ & $\begin{array}{c}\text { Number of } \\
\text { Classroom Teachers }\end{array}$ & $\begin{array}{c}\text { Number of } \\
\text { Librarians }\end{array}$ & $\begin{array}{c}\text { Support Staff } \\
\text { Time }\end{array}$ \\
\hline $\begin{array}{c}\text { School \#1 } \\
\text { Public }\end{array}$ & K-5 & $\begin{array}{c}\text { Primarily middle-to- } \\
\text { high }\end{array}$ & 560 & 19 & 1 \\
\hline $\begin{array}{c}\text { School \#2 } \\
\text { Public }\end{array}$ & K-6 & $\begin{array}{c}\text { Mixed; over half } \\
\text { low-middle }\end{array}$ & Not available & 17 & 1 \\
\hline $\begin{array}{c}\text { School \#3 } \\
\text { Private }\end{array}$ & $\begin{array}{c}\text { PreK-8 } \\
\text { (data } \\
\text { rected } \\
\text { reK-6) }\end{array}$ & Gifted students & 310 & 17 & 1 \\
\hline $\begin{array}{c}\text { School \#4 } \\
\text { Public }\end{array}$ & K-5 & Low-middle & 220 & 10 & 1 \\
\hline $\begin{array}{c}\text { School \#5 } \\
\text { Public }\end{array}$ & K-4 & Middle-upper middle & 600 & 26 & 1 \\
\hline $\begin{array}{c}\text { School \#6 } \\
\text { Public }\end{array}$ & K-6 & Mixed & 700 & 29 & 1 \\
\hline
\end{tabular}

Table 1 shows the great variation among the selected schools. Only pre-kindergarten (PreK) to 6 were included in data collection, although schools represented several different grade ranges. The schools varied in size and in source of financial support. One school had no support staff and another had only a half-time librarian. One school had a strong reading incentive program in which the library was heavily involved. 
Telephone interviews were conducted with the librarian, the principal, and a stratified random sample of three teachers from each school - one from PreK to grade 2, one from grades 3-6, and one from the entire list of teachers. The interview questions, determined from the responses in the Delphi study, were open-ended and qualitative, allowing respondents to expand in whatever direction they felt was appropriate.

\section{Librarian Interviews}

The librarian interviews were the most comprehensive, ranging from one to two hours. Most of the principal interviews took from twenty to thirty minutes, and teacher interviews lasted about fifteen minutes. A planned second interview with librarians, for confirmation, expansion, and elaboration had not occurred at the time of writing this paper.

Librarians were asked to provide an overview of flexible scheduling as it currently exists in their schools. They described how it works; whether any other kinds of scheduling are also used (e.g., fixed scheduling for kindergarten students); whether and how much support staff is available; how teacher planning time is provided; what kind of support exists for the concept in the administration, the teachers, and the district. They described the planning stage by explaining how the idea came about, what initial support was available, what planning process was used, and what problems had to be considered. They discussed problems that occurred during the implementation phase and what understandings were the most difficult to communicate to teachers during that phase.

Librarians were then asked about their personal characteristics that affected implementation, their reaction to change, and what kinds of relationships they had had with teachers at the time of implementation. They described the personal characteristics of teachers who work most effectively in a flexibly scheduled atmosphere, how the teachers plan and teach, and what teachers had to learn in order to make effective use of flexible scheduling. They were asked to describe principal characteristics that best supported implementation and what principals had to learn. They were asked about support from the district, from students, and from parents.

Librarians were also asked to discuss how things had changed during the years of implementation. How had the support changed? What staff development was carried out? How did collaborative planning occur? How much contact did the librarian have with students? How were records kept of information literacy? They were asked to indicate if they perceived any difference flexible scheduling had made to learning and what difference it had made to their jobs. They described barriers to continuing with flexible scheduling and the financial costs involved. They discussed the importance of the size of the collection, the size of the facility, the size of the school population, the amount of clerical help, the way teachers teach, and their own teaching philosophies. They were asked to discuss their hopes and fears for the future: what changes would they like to implement and how? They were asked to provide advice to librarians wanting to implement flexible scheduling with and without the support of the principal. 


\section{Principal Interviews}

Principals were also asked to define and describe flexible scheduling as it works in their schools. They described their roles in implementation, why they had supported flexible scheduling, and what their prior knowledge and experience had been. They described the demands made on a principal; the advantages and disadvantages of flexible scheduling; the benefits to students, teachers, and librarians; the implementation process; the problems they had dealt with, and the solutions to those problems; and the fiscal implications of flexible scheduling. They identified characteristics of librarians and teachers that make flexible scheduling work. They described their perceptions about differences brought about by flexible scheduling, such as differences in their own thinking, in the way their teachers teach, and in the student learning or behavior. They provided advice to administrators and librarians considering flexible scheduling.

\section{Teacher Interviews}

Teachers were asked to define flexible scheduling and describe how it affects them and their students. They were asked to identify benefits and problems associated with flexible scheduling. If they were in that school during implementation, they provided their impressions about how it took place and described how they had felt about the idea initially. They then described whether and how their feelings or their teaching had changed, the professional development they had received, and how their students gained information skills.

\section{Results/Findings}

Findings at the time of writing this paper are preliminary, since circumstances forced postponement of the final stage of interviews with the school librarians. A number of patterns have emerged at this point, however, which will be confirmed and expanded with this final set of interviews.

Participants were not given a definition of flexible scheduling, since the term has many interpretations and variations of use. Instead, they were asked to provide their own definition and to explain how flexible scheduling works in their schools in order to get a sense of the variations that existed among the different sites. Each participant answered this question a little differently, with some emphasizing learning outcomes that result and some emphasizing flexible access to materials. The application of flexible scheduling varied from some fixed at the lower grades to complete flexibility at all grade levels.

Principal's descriptions of flexible scheduling typically dealt with access for students at the point of need, although one principal saw it as a way for teachers to be able to plan and conduct resource-based units for their students. They emphasized meeting needs at the appropriate time and the ability to provide constant and consistent service. 
Several patterns, to be confirmed and/or extended by the final interviews with the librarians, are stated here as preliminary assertions.

The first assertion is that, in each case, a particular educational need drove the move to flexible scheduling. In four schools, the desire to create or further implement an integrated curriculum was emphasized. In one the implementation of flexible scheduling was driven by a strong literacy focus, tied to an intense reading promotion initiative. In the sixth, the push came from a desire to support the curriculum in a more meaningful way, but it also was related to facilitating a strong reading initiative. In all cases the scheduling promoted both of these foci, but the original drive and incentive varied. Flexible scheduling driven by internal curriculum needs contrasts with schools in the Library Power program (Shannon, 1996; Zweizig, 1999), in which flexible scheduling was a requirement for participation in the program. In Library Power schools implementation was driven by an external force (funding) and the link to curriculum or literacy support came as another requirement of the program. In those schools, the requirement for flexible scheduling to be in place might have created the opportunity to make curriculum integration work. Teachers, however, might have seen flexible scheduling as an end, not a means. Flexible scheduling in all cases in the present study was only an instrument, a tool to make something else work. It was never an end in itself. While flexible scheduling and the other element for which it was implemented might have happened concurrently, flexible scheduling did not cause the other element. This fact seems to support Ken Haycock's suggestion that the existence of flexible scheduling may say more about leadership practices and collaborative ideas than it does about why consultation occurs (Haycock, 1998). In all cases, flexible scheduling only provided a means for consultation between teachers and librarians to take place. It did not cause that consultation to happen. The fact that flexible scheduling existed could be attributed to the leadership of various people in the school, and to the acceptance by at least some of the stakeholders of the idea of collaboration.

Another assertion is that the principal's support was critical. Librarians emphasized this and described ways in which that support was provided. Principals, too, were aware that their support was key in the successful implementation. Interestingly, in one case, where the librarian was not completely satisfied with the support that the principal had given, the principal in that case stated strong support for the concept of flexible scheduling and believed that sufficient support had been provided. It seemed that the two did not have the same definition of principal support! While the librarian wanted the principal to be vocal and active about the support, requiring teachers to cooperate, the principal believed that support had been provided by concurring with the strategies the librarian planned to use. The principal believed that more active involvement was unnecessary because the librarian was doing such a wonderful job. Better communication between principal and librarian of how each perceived appropriate support would have helped both to understand the reactions of the other and perhaps eased this librarian's concerns.

Tied to this need for a principal's support is the need for education of principals. Most principals admitted that they had little or no knowledge of the concept of flexible scheduling before the idea was broached by their librarian. They described the education they received 
from their librarians and emphasized that the benefits to students was the selling feature. Some of the librarians described the need to convince their principals of the value of flexible scheduling by making them familiar with successful examples, either in person or through reading articles.

A third preliminary assertion is that implementation was less stressful when the schools devised acceptable alternatives to providing teacher planning time. Traditionally, teachers get planning time when specialists take over classes to relieve the teacher of direct teaching responsibility for a period of time. Often the librarian has been one of the specialists involved as students rotate through the various specialists' subjects. Where creative solutions were implemented to take librarians out of this rotation, teacher objections seemed to be fewer. One school, for example, created a science lab time, which complemented a current thrust to improve students' science skills. The principal emphasized, however, that this was a staff decision, not the principal's alone. The decision was made because teachers were interested in making better use of their library media center and were willing to have slightly larger classes to accommodate the changes. Another school provides a frequently changing elective program, where all teachers and staff (and some parents and other community members) offer interesting options for students. During this option period, teachers take turns at using the time for their planning and do not offer an option on that day. Another school increased the subjects included in the rotation by adding a computer program and a literacy program to the typical art, music, and physical education classes.

A fourth assertion is that the personal qualities of the librarian appeared to be very important to successful implementation. Principals extolled their librarians' virtues and suggested that flexibility, energy, a sharing and facilitating mindset, competence, persistence, awareness of national trends and best practice, a sense of humor, enthusiasm, and an ability to deal with many different kinds of people were all important. The most commonly mentioned characteristic was flexibility. The librarians described themselves as enthusiastic, energetic, organized, accommodating, reliable, inquisitive, risk-taking, willing to experiment, not uncomfortable with change, hard-working, and willing to compromise and adapt to meet teachers' needs. Again, the characteristic that kept recurring in many of their answers and anecdotes was flexibility. Teachers also mentioned flexibility as an important characteristic of a librarian who wishes to implement and successfully carry out flexible scheduling.

Most stakeholders identified support staff as playing a crucial role in successful implementation, because services could be provided that enable librarians to work directly with teachers and students. Surprisingly, though, one librarian has no support staff and minimal volunteer assistance. In spite of that, she is able to carry off a relatively successful flexibly scheduled program that emphasizes curriculum integration. She did agree that having support staff assistance would make the program much easier to conduct successfully and expressed a wish for more assistance. She was prepared, however, to deal with a projected increased student population in the coming school term, which would mean a growth from 250 to 900 students since she began flexible scheduling several years ago.

Each school was in a slightly different situation as the idea of flexible scheduling was broached. In each case, the approach to implementation varied depending on the situation (the sixth assertion). In some cases, curriculum integration was mandated from the district administration, and schools were expected to follow the mandate. In these cases, the mandate 
was intended to increase the role of the librarian in curriculum integration and resource-based learning. Flexible scheduling was instituted to make this type of teaching and learning possible. In these cases, the approach to implementation was simply to work out whatever problems might arise and institute the program across the board. Teachers were given some professional development at the beginning to promote effective use of the library under the new form of scheduling. In other cases, the librarian knew that rigid scheduling did not provide the best learning situation for the children and became determined to bring about change. The approach in these cases was more evangelistic, with the librarian convincing the principal first and then at least some of the teachers that the idea could work. Sometimes flexible scheduling was implemented gradually, perhaps a grade at a time. Although convinced by the librarian that the idea was sound, one principal waited for the right moment before she pushed for flexible scheduling. When a committee of teachers examined another school program and recommended change, she realized that not only was this the right moment to bring in flexible scheduling, but also it was the moment to move the library to the room vacated by the other program, a move that made concurrent multiple activities in the library possible. This principal maintained that if the implementation of flexible scheduling had not occurred at the right moment, it would not have had the success it did. In all cases, the librarian believed in the value of the change at the beginning, whether or not anyone else did.

A seventh preliminary assertion, based only on perceptions not testing, is related to the difference flexible scheduling (and its related curriculum innovations) has made to students. Stakeholders described students as being more motivated and exited about learning, They suggested that learning and the library are both more relevant to students because they know they need the information and the skills related. Children have changed from being passive recipients of knowledge to being active learners. Students now consider the library as a primary source of information, not an afterthought.

Another assertion is that librarians and principals typically perceived the costs of flexible scheduling differently. Most librarians identified no fiscal implications to flexible scheduling, or suggested only that an improved collection was a potential cost. Principals recognized the need for improved collections, but several also pointed out the cost of support staff and of maintaining a full time librarian.

A final preliminary assertion is that acceptance typically comes slowly. Though some of these librarians were tempted to abandon the idea because of resistance from teachers, they all expressed the importance of persisting, of not being discouraged by seeming indifference or resistance, of looking for small successes and building on those over a period of years, not just months. While they did not name patience as a virtue, they certainly could have done so.

\section{Recommendations from Participants}

Librarians, principals, and teachers were all asked to make recommendations that would promote successful implementation.

- Visit successful sites together to study how to implement effectively. Include principals, teachers, and librarians in these visits. 
- Form district committees of teachers to study the concept and bring the study's findings back to the school

- "Just wait for the right moment and then seize it" (principal quote).

- Teachers do not know how to take advantage of the situation; they must be taught how to make the best of it.

- The librarian will have to make something happen in the beginning. Actively seek out people to with whom to plan or the place will be empty.

- Keep a visible public schedule so everyone can see what's happening in the library.

- Loan out rotating and constantly changing classroom libraries to provide regular access to a collection of reading material. Teachers might be more comfortable with their classes not coming to the library for a weekly book checkout if the students have ready access to books.

- Be able to accept disorganization, uncertainty, and change.

- Be aware that you can't please all of the people all of the time.

- Be intuitive - figure out where teachers are, meet them wherever they are, and bring them along a continuum of effective use.

- Plan as a district to continually educate new superintendents and administrators.

- Plan to educate new administrators and teachers locally.

- Conduct inservices for each other in other schools.

\section{Preliminary Conclusions and Recommendations}

It is difficult to draw conclusions without having collected the final dataset. However, it appears that in successful cases of implementation, flexible scheduling is only a tool. It is not an end in itself. It is important to promote the benefits for student learning, not the flexible scheduling concept itself. Flexible scheduling is a concept that might be familiar to librarians but is less likely to be familiar to principals and teachers. Education of those who will be affected by flexible scheduling is essential, because they are unlikely to already understand its goals and benefits.

As an illustration, when librarians discussed about flexible scheduling they typically spoke as much about the educational initiative that had driven flexible scheduling in the first place as about the mechanism that had enabled that initiative. When they discussed the difference in students, or the evidence of student learning, they described the effects of resource-based learning or unlimited access to a collection of reading materials instead of limiting their discussion to the concept of flexible scheduling. Teachers and principals, on the other hand, were more likely to discuss flexible scheduling as a separate concept, not necessarily tied to an educational initiative. They did describe the independence of the children, the willingness to search for information to solve a problem, the switch from a passive to an active learning role, but typically did not make the point that the change was related to an educational initiative as much as it was to the change in scheduling practice.

Caution must be exercised in generalizing from these findings and conclusions. Not only are they preliminary, they were based on a very small sample. Some early recommendations do seem to be in order, however, with the proviso that anyone attempting to follow these 
recommendations be aware that their own situation might not parallel the schools in the study.

Librarians hoping to implement flexible scheduling will need to promote the program, not the schedule. They must promote the concept of flexible scheduling in terms of what teachers (and students) stand to gain. Librarians must convince teachers that they can provide a service that teachers need and that flexible scheduling is an effective mechanism to provide this service. Education of administrators and teachers is crucial, again emphasizing the benefits to learning. Librarians can provide principals and teachers with reading material to begin the educational process. They can also "model" the results by working with a single teacher or grade level to demonstrate the process and the benefits of flexible scheduling. This should lessen the concerns of principals and teachers and inspire other teachers to get involved too.

\section{References}

Donham van Deusen, Jean. (1995). Prerequisites to flexible planning. Emergency Librarian, 23 (1), 16-19.

Haycock, Ken. (1997). The impact of scheduling on cooperative program planning and teaching (CPPT) \& information skills instruction. School Libraries in Canada, 18 (3), 20-23.

Shannon, Donna. (1996). Tracking the transition to a flexible access library program in two Library Power elementary schools. School Library Media Quarterly, 24 (3), 155-163.

Tallman, Julie, \& Donham van Deusen, Jean. (1994). Collaborative unit planning-Schedule, time, and participants. Part Three: The 1993-1994 AASL/Highsmith Research Award Study. School Library Media Quarterly, 23 (1), 33-37.

Zweizig, Douglas. (1999). Access and use of library resources in Library Power. School Libraries Worldwide, 5 (2), 16-28. 